\title{
Low Molecular Weight Organic Acid Complexation Affects Antimony(III) Adsorption by Granular Ferric Hydroxide
}

Xiaochen $\mathrm{Li}^{1,2}$, Tatiana Reich ${ }^{2}$, Michael Kersten ${ }^{2, *}$, Chuanyong Jing ${ }^{1,3 * *}$

${ }^{1}$ State Key Laboratory of Environmental Chemistry and Ecotoxicology, Research Center for EcoEnvironmental Sciences, Chinese Academy of Sciences, Beijing 100085, China

${ }^{2}$ Geosciences Institute, Johannes Gutenberg University, Mainz 55099, Germany

${ }^{3}$ University of Chinese Academy of Sciences, Beijing 100049, China

*,**Corresponding author emails: kersten@uni-mainz.de, cyjing@rcees.ac.cn

\section{SUPPORTING INFORMATION}

16 pages with with 9 Figures and 3 Tables

1. Mineralogical characterization of the synthesized akaganéite sample and granular ferric hydroxide $\quad$ S2

2. Aqueous $\mathrm{Sb}$ speciation analysis

3. XANES and EXAFS data for the reference minerals and structural models

4. $\mathrm{Sb}$ (III) speciation in the presence of tartrate

5. Langmuir isotherm for $\mathrm{Sb}(\mathrm{III})$ adsorption by $\mathrm{GFH}$

6. Tartrate surface complexation model

7. $\mathrm{Sb}(\mathrm{V})$ surface complexation model

8. Surface complexation model without tartrate complexation in solution

9. PhreePlot script for the pe-pH diagram 


\section{Mineralogical characterization of the synthesized akaganéite sample and granular ferric hydroxide}

The pure akaganéite synthesis involved slowly hydrolysing $1 \mathrm{M} \mathrm{FeCl}_{3}$. The $\mathrm{FeCl}_{3}$ solution was prepared by dissolving $269 \mathrm{~g}$ of $\mathrm{FeCl}_{3} \cdot 6 \mathrm{H}_{2} \mathrm{O}$ (Merck) in $1 \mathrm{~L}$ of deionized water at room temperature, then adding 750 $\mathrm{mL}$ of $1 \mathrm{M} \mathrm{KOH}$ (Merck) dropwise over $\sim 2 \mathrm{~h}$. The reddish-brown solution was then maintained at $70{ }^{\circ} \mathrm{C}$ in a sealed $2 \mathrm{~L}$ glass bottle for $8 \mathrm{~d}$, during which the solution became lighter in colour and a compact lightbrown precipitate was formed. The mixture was centrifuged and the supernatant was removed and replaced with deionized $\mathrm{CO}_{2}$-free water. The suspension was adjusted to $\sim \mathrm{pH} 7$ by adding $5 \mathrm{M} \mathrm{KOH}$ (Merck) dropwise, then the precipitate was collected by centrifuging the suspension three times. The dry weight and phase purity of the product was checked by XRD upon drying a subsample (Figure S1). Aliquots of the undried fine-grained material equal to $1 \mathrm{~g} \mathrm{~L}^{-1}$ dry weight were equilibrated with solutions at $\mathrm{pH} 4,7$, and 10 containing Sb(III) concentrations between 1200 and $1650 \mathrm{mg} \mathrm{L}^{-1}$ (Table S1). The wet pastes produced after centrifuging the suspensions were sealed in small polyethylene tubes, then the tubes were placed in a desiccator filled with Ar and frozen for X-ray spectroscopic analysis. The synthesized pure akaganéite sample and granular ferric hydroxide (GFH) were mineralogically characterized by X-ray diffractometry (XRD) using a Huber 423 diffractometer with Co radiation at $40 \mathrm{kV}$ and $20 \mathrm{~mA}$. The samples were disaggregated and homogenized using a McCrone Mill using anatase $\left(\mathrm{TiO}_{2}\right)$ powder as an internal standard. The samples were milled for a maximum of a few minutes because phase transformation could have occurred if the samples had been milled for longer [1]. The XRD results indicated that the akaganéite sample was a pure phase [2], and that the GFH sample was a mixture of $55 \%$ by dry weight akagenéite and $45 \%$ by dry weight 2-line ferrihydrite [3].

Figure S1. XRD patterns for akaganéite and GFH.

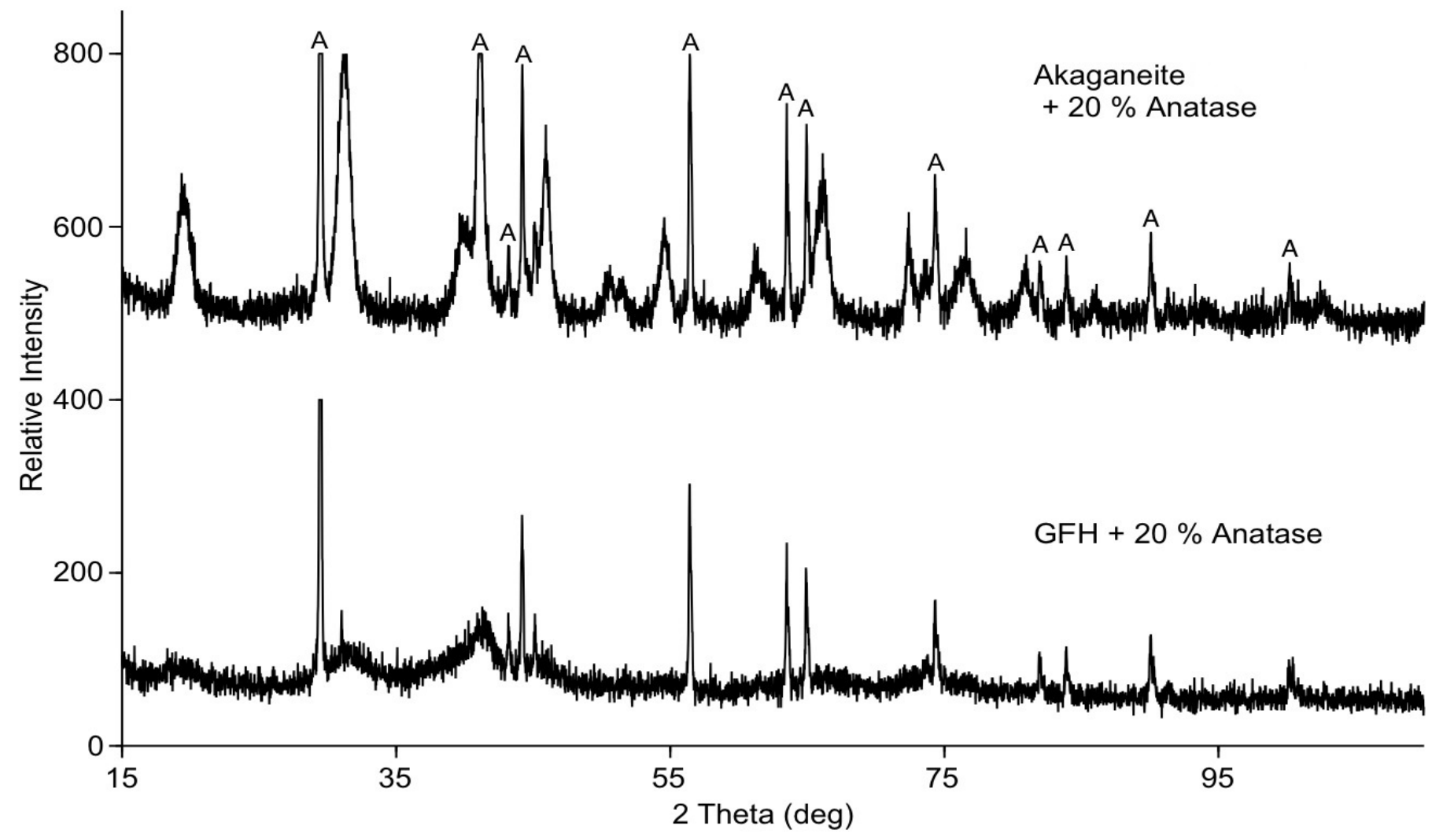




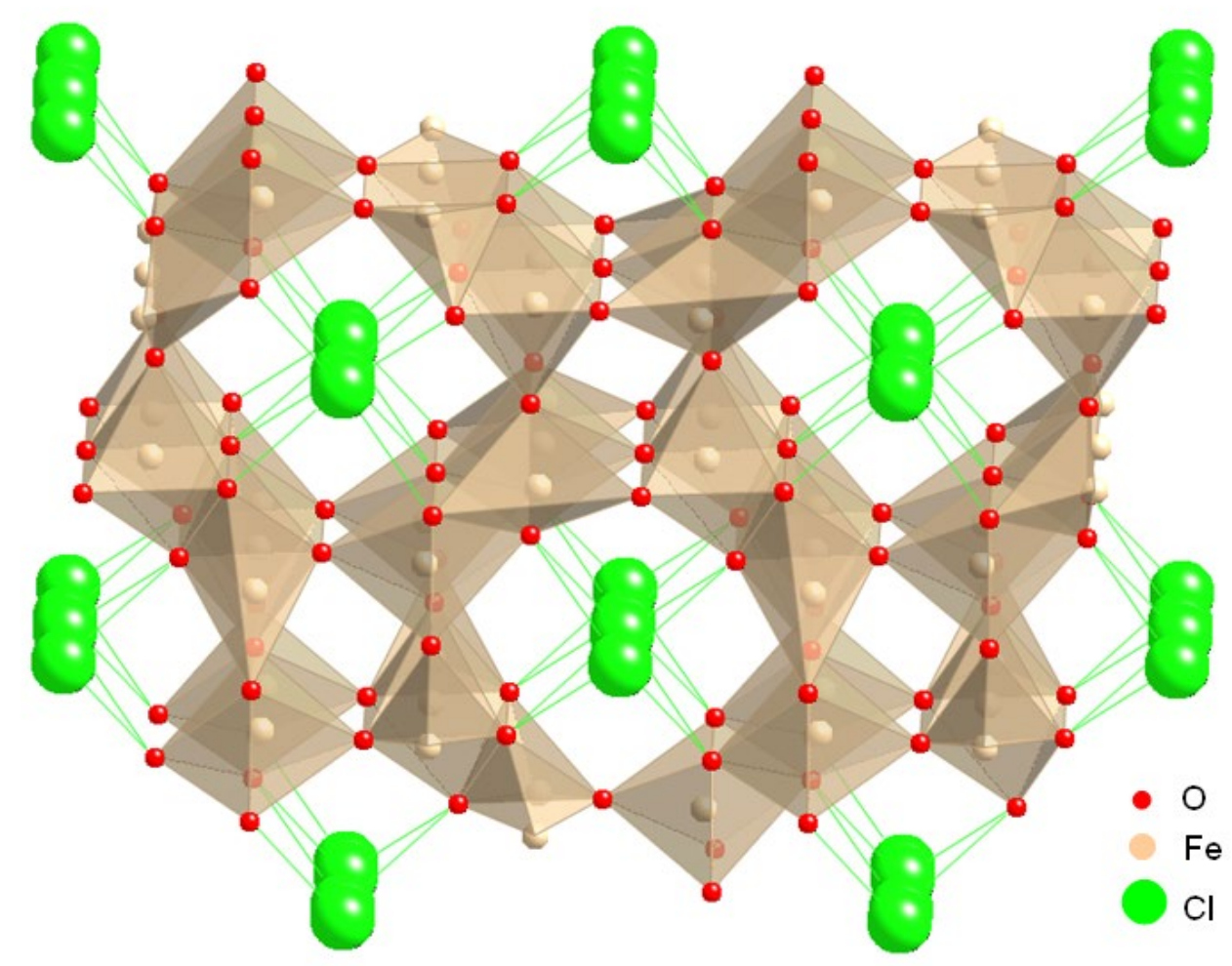

Figure S2. The crystal structure of akaganéite generated using the CrystalMaker software package and the XRD data published by Post et al. 2003 [2].

\section{Aqueous Sb speciation analysis}

Differential pulse anodic stripping voltammetry (DPASV) was used to measure the concentrations of different $\mathrm{Sb}$ species in the solutions after the batch equilibration adsorption experiments had been performed. A Metrohm Computrace Model 797 DPASV instrument was used. The working electrode was a hanging mercury drop electrode, and a $\mathrm{Pt}$ auxiliary electrode and $\mathrm{Ag} / \mathrm{AgCl}$ reference electrode were also used. Each filtered $10 \mathrm{~mL}$ sample was de-aerated with Ar for $5 \mathrm{~min}$, then $0.6 \mathrm{~mL}$ conc. $\mathrm{HCl}(30 \%$ Merck Suprapure) was added. Using $0.6 \mathrm{~mol} \mathrm{~L}^{-1} \mathrm{HCl}$ as the supporting electrolyte during anodic stripping voltammetry caused well-defined oxidation peaks (Figure S3), and the limit of determination for Sb(III) was $5 \mathrm{nmol} \mathrm{L}{ }^{-1}$. The limit of determination increased linearly as the $\mathrm{HCl}$ concentration increased (i.e., a factor of five worse at $3.0 \mathrm{~mol} \mathrm{~L} \mathrm{~L}^{-1} \mathrm{HCl}$ than at $\left.0.6 \mathrm{~mol} \mathrm{~L}^{-1} \mathrm{HCl}\right)$. All measurements were carried out using a pulse height of $10 \mathrm{mV}$, a scan rate of $20 \mathrm{mV} \mathrm{s}^{-1}$, and a $4 \mathrm{mV}$ scan increment, as recommended in methods $2 \mathrm{a}$ (for $\mathrm{Sb}(\mathrm{III})$ ) and $2 \mathrm{~b}$ (for $\mathrm{Sb}(\mathrm{V})$ ) described in Metrohm Application Bulletin 74. The potential was swept from -450 to $-70 \mathrm{mV}$ after $\mathrm{Sb}$ had been deposited in the $\mathrm{Hg}$ drop at $-400 \mathrm{mV}$ for $1-3 \mathrm{~min}$ (depending on the concentration). Working solutions were prepared each day by diluting a $1 \mathrm{~g} \mathrm{~L}^{-1} \mathrm{SbCl}_{3}$ standard solution in $1.8 \mathrm{~mol} \mathrm{~L}^{-1} \mathrm{HCl}$ (Merck Titrisol), and the $\mathrm{Sb}$ concentration in each sample was determined using two standard additions (see below). Tartrate did not markedly interfere with the $\mathrm{Sb}$ analysis. Total $\mathrm{Sb}$ ( $\mathrm{Sb}(\mathrm{III})+$ $\mathrm{Sb}(\mathrm{V})$ ) was measured by increasing the $\mathrm{HCl}$ concentrations in the samples to $3.0 \mathrm{~mol} \mathrm{~L}^{-1}$. 

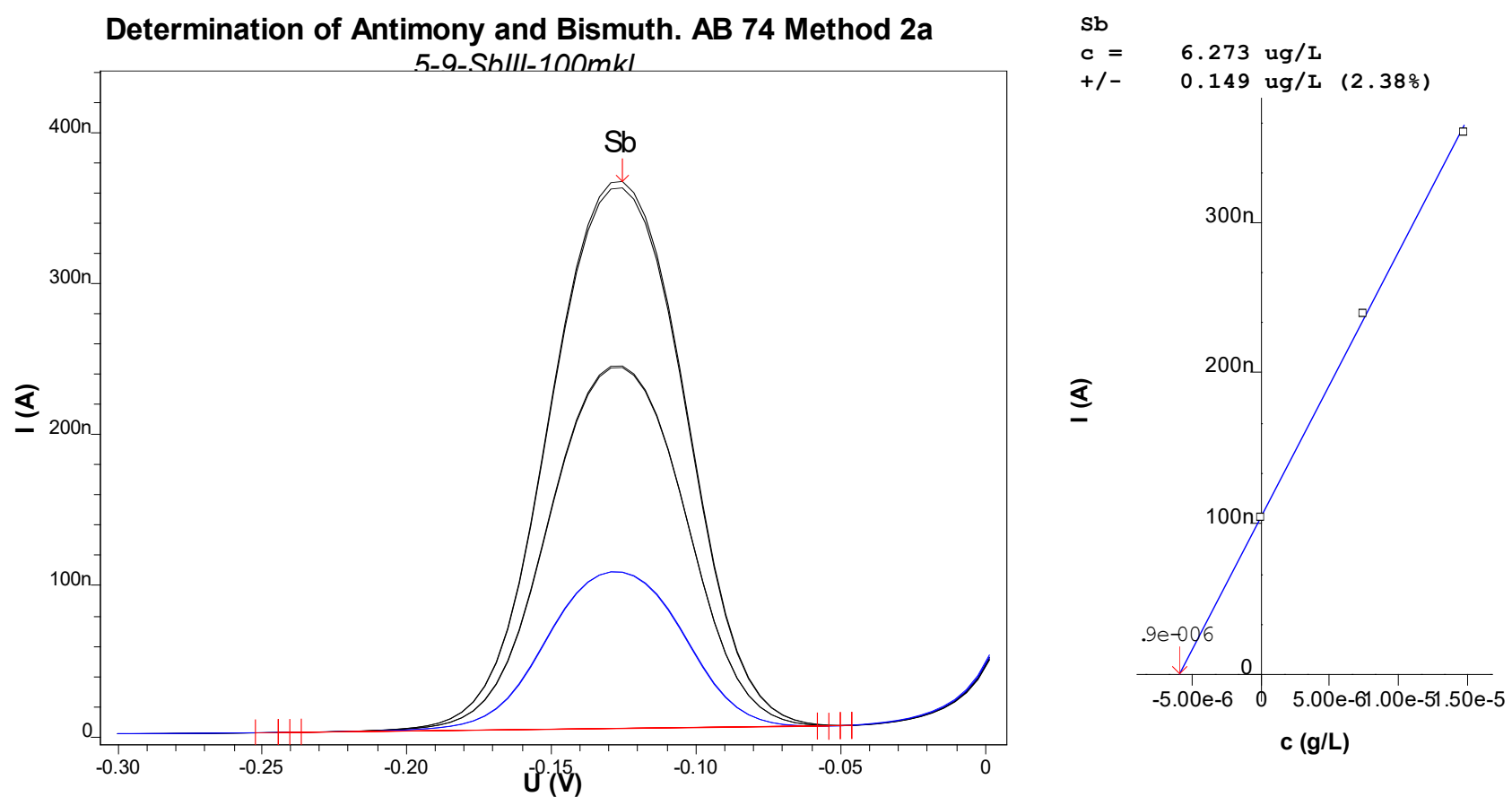

Determination of Copper and Antimon or Bismuth. AB 74 Method 2b

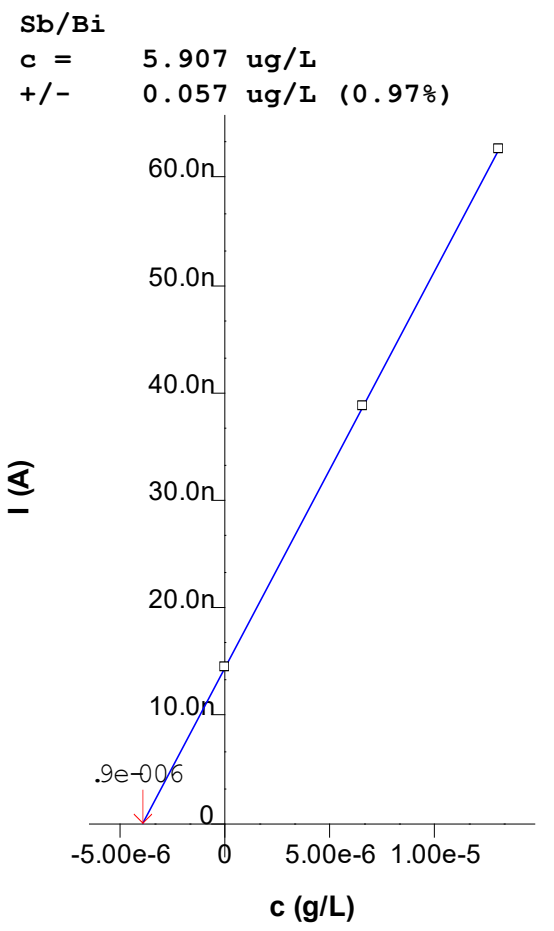

Figure S3: Typical DPASV voltammograms (potential in V plotted against current in $\mathrm{nA}$ ) for the aqueous supernatant samples from the batch equilibration adsorption experiment (blue peaks) with standard additions (black peaks). A HCl concentration of $0.6 \mathrm{~mol} \mathrm{~L}^{-1}$ was used for the data shown in the upper voltammogram to detect $\mathrm{Sb}$ (III) only, and a $\mathrm{HCl}$ concentration of $3.0 \mathrm{~mol} \mathrm{~L}^{-1}$ was used for the data shown in the lower voltammogram for the total $\mathrm{Sb}$. The concentrations were not markedly different despite the difference in the peak heights, indicating that the total $\mathrm{Sb}$ was all present as $\mathrm{Sb}(\mathrm{III})$. 


\section{XANES and EXAFS data for the reference minerals and structural models}

Table S1. Summary of Sb loaded sorption samples examined by XAFS

\begin{tabular}{|c|c|c|c|c|}
\hline Sample & Absorbent & Initial Sb oxidation state & $\mathrm{pH}$ & Sb loading (ppm) \\
\hline 1 & akaganéite & III & 4 & 1450 \\
\hline 2 & akaganéite & III & 7 & 1650 \\
\hline 3 & akaganéite & III & 10 & 1200 \\
\hline
\end{tabular}

Table S2. Results of the least-squares refinement of EXAFS data for the $\mathrm{Sb}(\mathrm{III})$ reference mineral schafarzikite and XRD data [4]. The distances to the Sb neighbours $r$ were $\pm 0.02 \AA$, the Debye-Waller factors $\sigma^{2}$ were $\pm 0.004 \AA^{2}$, and $\chi^{2}$ res was 0.11 .

\begin{tabular}{|c|c|c|c|c|c|c|c|c|c|c|c|c|}
\hline \multirow{3}{*}{$\begin{array}{l}\text { Standard } \\
\text { Spectrum }\end{array}$} & \multicolumn{2}{|c|}{$\mathrm{O}_{1}$} & \multicolumn{2}{|c|}{$\mathrm{O}_{2}$} & \multicolumn{2}{|c|}{$\mathrm{Fe}_{1}$} & \multicolumn{2}{|c|}{$\mathrm{Sb}_{1}$} & \multicolumn{2}{|c|}{$\mathrm{Fe}_{2}$} & \multicolumn{2}{|c|}{$\mathrm{Sb}_{2}$} \\
\hline & \multicolumn{4}{|c|}{$\sigma^{2}=0.0036^{*}$} & \multicolumn{6}{|c|}{$\sigma^{2}=0.0080^{*}$} & \multicolumn{2}{|c|}{$\sigma^{2}=0.0160$} \\
\hline & $r$ & $N$ & $r$ & $N$ & $r$ & $N$ & $r$ & $N$ & $r$ & $N$ & $r$ & $N$ \\
\hline $\mathrm{FeSb}_{2} \mathrm{O}_{4}$ & 1.94 & 1.2 & $1.99^{*}$ & $2.34^{*}$ & 3.47 & 2.2 & $3.54^{*}$ & $2.2^{*}$ & $3.59^{*}$ & $2.2^{*}$ & 4.17 & 4.3 \\
\hline XRD [1] & 1.93 & 1 & 1.99 & 2 & 3.46 & 2 & 3.53 & 2 & 3.58 & 2 & 4.16 & 5 \\
\hline
\end{tabular}

* parameter correlated during the least-squares fitting process

Table S3. Results of the least-squares refinement of the EXAFS data for the $\mathrm{Sb}(\mathrm{V})$ reference mineral tripuhyite and XRD data [5]. The distances to the Sb neighbours $r$ were $\pm 0.02 \AA$, the Debye-Waller factors $\sigma^{2}$ were $\pm 0.004 \AA^{2}$, and $\chi^{2}$ res was 0.33 .

\begin{tabular}{|c|c|c|c|c|c|c|c|c|c|c|c|c|c|}
\hline \multirow{3}{*}{\multicolumn{2}{|c|}{$\begin{array}{l}\text { Standard } \\
\text { Spectrum }\end{array}$}} & \multirow{2}{*}{\multicolumn{2}{|c|}{$\begin{array}{l}\mathrm{O}_{1} \\
\sigma^{2}=0.0041\end{array}$}} & \multirow{2}{*}{\multicolumn{4}{|c|}{$\begin{array}{l}\mathrm{Fe}_{1} \\
\sigma^{2}=0.0040^{*}\end{array}$}} & \multirow{2}{*}{\multicolumn{4}{|c|}{$\begin{array}{l}\mathrm{Fe}_{2} \\
\sigma^{2}=0.0049^{*}\end{array}$}} & \multirow{2}{*}{\multicolumn{2}{|c|}{$\begin{array}{l}\mathrm{Sb}_{3} \\
\sigma^{22}=0.0036\end{array}$}} \\
\hline & & & & & & & & & & & & & \\
\hline & & $r$ & $N$ & $r$ & $N$ & $r$ & $N$ & $r$ & $N$ & $r$ & $N$ & $r$ & $N$ \\
\hline $\mathrm{FeSbO}_{4}$ & $100 \mathrm{~K}$ & 1.97 & 6.6 & 3.08 & $1^{\#}$ & $3.08^{*}$ & $0.5^{\#}$ & 3.62 & $5^{\#}$ & $3.62^{*}$ & $3^{\#}$ & 4.67 & $1^{\#}$ \\
\hline XRD [2] & & $\begin{array}{l}1.99 / \\
2.02\end{array}$ & $\begin{array}{l}4 / \\
2\end{array}$ & 3.08 & 1 & 3.08 & 1 & 3.63 & 5 & 3.63 & 3 & 4.64 & 1 \\
\hline
\end{tabular}

* parameter correlated during the least-squares fitting process

\# parameter fixed during the least-squares fitting process 
Figure S4. Structural models of two potential antimonite surface complex modes (the blue tetrahedra on the left and right are the ${ }^{2} \mathrm{E}^{5}$ and ${ }^{2} \mathrm{C}$ variants, respectively) for pure akaganéite at alkaline $\mathrm{pH}$ values.

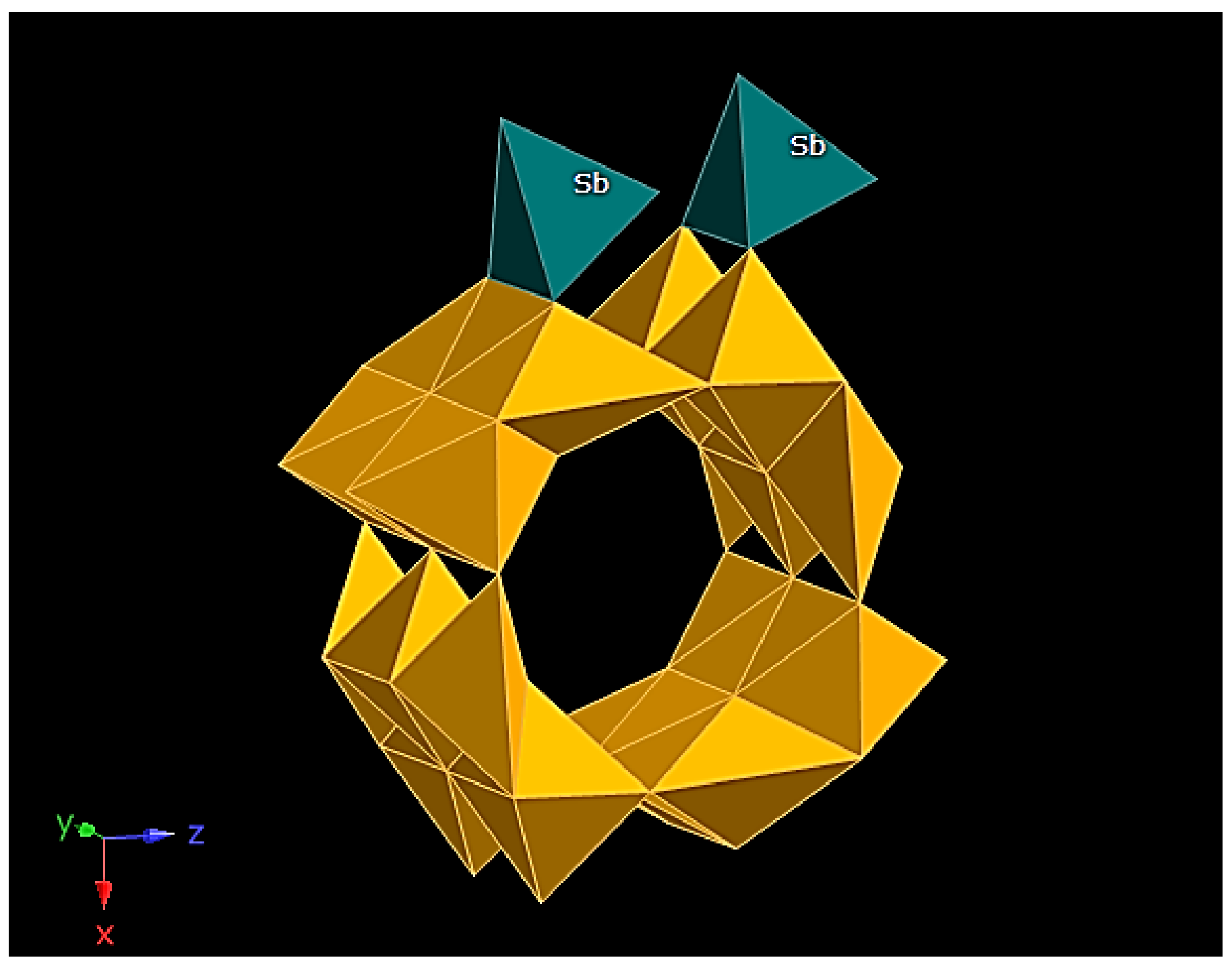




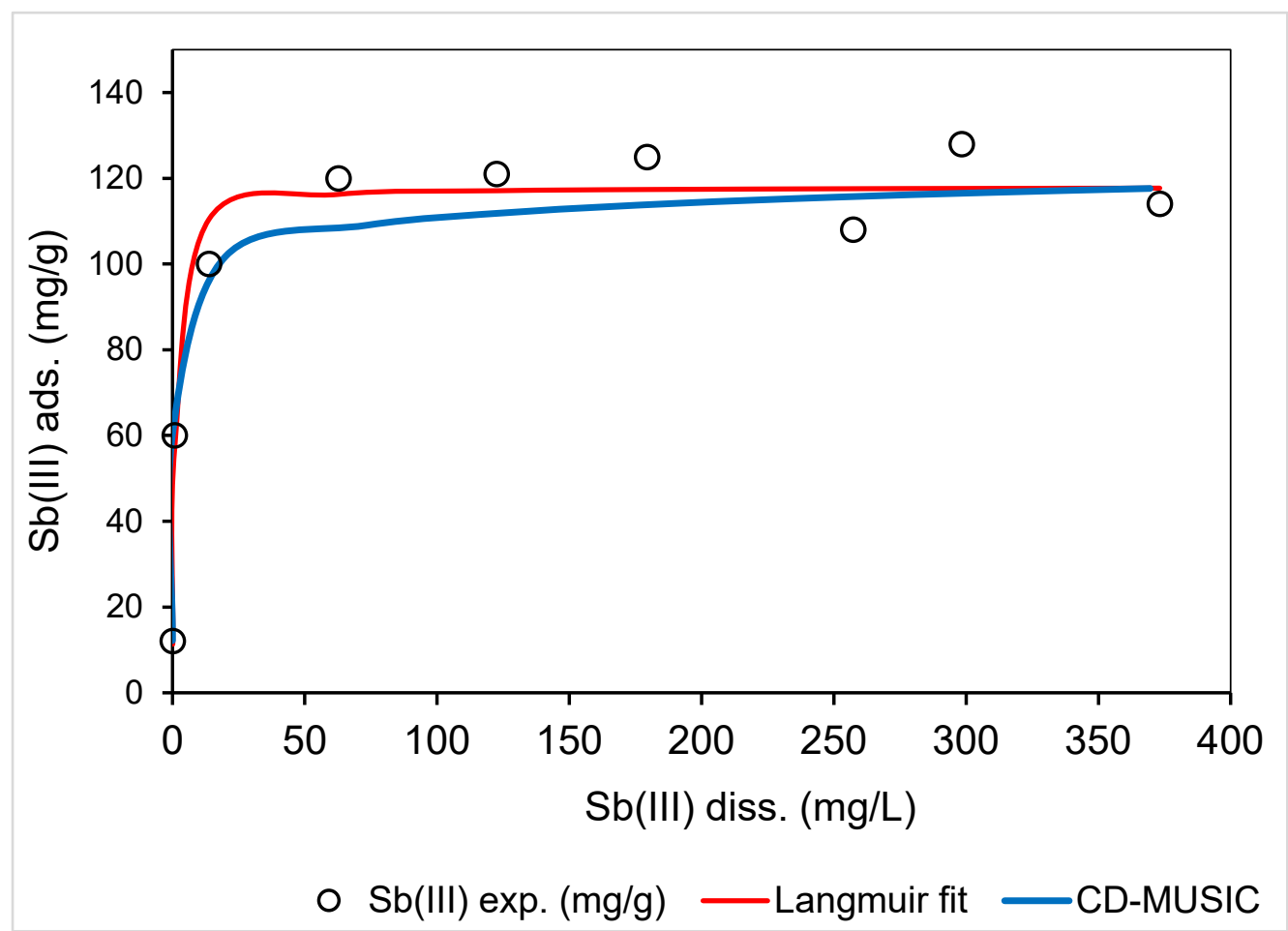

Figure S5. Best fit curves by Langmuir isotherm (EXCEL Solver fit, red line) and CD-MUSIC model (Visual MINTEQ fit, blue line) for batch experiment data (black circles) of Sb(III) adsorption by $1 \mathrm{~g} / \mathrm{L}$ GFH at $\mathrm{pH} 4.8$.

\section{5. $\mathrm{Sb}(\mathrm{III})$ speciation in the presence of tartrate}

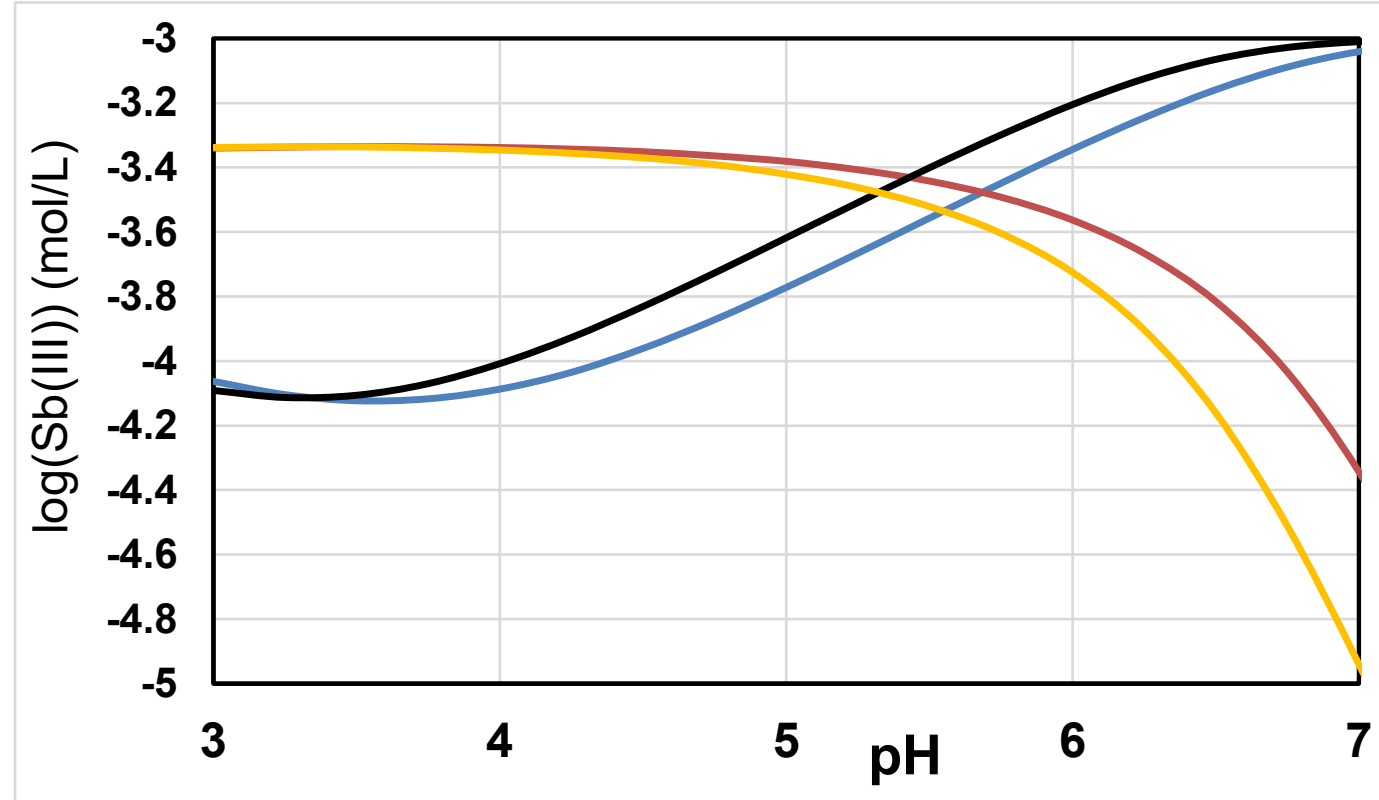

$\mathrm{Sb}(\mathrm{OH}) 3$ Conc. (10 mM NaNO3)

$\longrightarrow \mathrm{Sb}(\mathrm{OH}) 3$ Conc. (100 mM NaNO3)
- Sb2Tar2-2 Conc. (10 mM NaNO3) Sb2Tar2-2 Conc. (100 mM NaNO3)
Figure S6. Sb(III) speciation in the presence of tartrate (total concentration 1 mmol L ${ }^{-1}$ ) at two different $\mathrm{NaNO}_{3}$ background electrolyte concentrations (10 and $100 \mathrm{mmol} \mathrm{L}^{-1}$ ) modelled using the VMINTEQ code using the $\log K$ values shown in Table 2 (main text). Note the increase in free $\mathrm{Sb}(\mathrm{OH})_{3}^{0}$ as the background electrolyte concentration increases above $\mathrm{pH} 4$. 


\section{Tartrate surface complexation}

The number of surface reactions necessary to fit organic acid adsorption data depends on several factors, including the number of acidic functional groups and the $\mathrm{p} K_{\mathrm{a}}$ range. For the structure of tartaric acid, HOOC $-\mathrm{CH}(\mathrm{OH})-\mathrm{CH}(\mathrm{OH})-\mathrm{COOH}$, the two carboxylic groups can both be assumed to react with $\mathrm{Fe}$ hydroxide surfaces in binuclear bidentate coordination [6]. Deprotonation of the two carboxylic groups occurs at acidic $\mathrm{pH}$ in two steps $\left(\mathrm{p} K_{\mathrm{a} 1}=2.95, \mathrm{p} K_{\mathrm{a} 2}=4.25\right)$. A proportion of the tartaric acid becomes adsorbed at acidic pH (Figure S7). The background electrolyte had no marked effects on the adsorption curves. We therefore assumed that the data could be fitted taking only inner-sphere surface complexation reactions involving both deprotonated groups into account. When setting up such reactions with appropriate $\log K$ and CD-MUSIC values, we assumed that only singly coordinated surface groups $\equiv \mathrm{FeOH}^{-0.5}$ were reactive in terms of inner-sphere complexation of tartrate, and we took the steric structure of the tartaric molecule into consideration. We further assumed that, at the most acidic $\mathrm{pH}$ values, both carboxyl groups would form coordinative hydrogen-bonded bidentate binuclear complexes involving direct hydrogen bonds between the carboxyl moieties and surface hydroxyl groups (charge distribution $\Delta z_{0}=+1$ for the inner Helmholtz 0-plane). The two surface hydroxyl groups would therefore be protonated to form surface water groups, which would subsequently be released leading to a net ligand exchange reaction. This interpretation accords with, for example, phthalate sorption to goethite, in which similarly hydrogen-bonded surface complexes are involved with two surface hydroxo groups in the basal planes [6].

The equation for this adsorption reaction is

$$
2 \equiv \mathrm{FeOH}^{-0.5}+\operatorname{Tar}^{-2}+2 \mathrm{H}^{+} \leftrightarrow(\equiv \mathrm{FeO}){ }_{2}^{\Delta z_{0}} \operatorname{Tar}^{\Delta z_{1}}+2 \mathrm{H}_{2} \mathrm{O}
$$

The somewhat inconsistent notion of $\mathrm{H}_{2} \mathrm{Tar}^{-2}$ being equal to $\mathrm{Tar}^{-2}$ is used in previous publications, neglecting the two protonated alcoholic hydroxyl groups in the latter term. It should be noted that the two $\equiv \mathrm{FeOH}$ moieties in the equation do not denote the number of $\mathrm{Fe}(\mathrm{O}, \mathrm{OH})_{6}$ octahedra but only the number of surface sites that may or may not have the same octahedral for binding the organic molecule. With respect to the ligand charge distribution, half the charge of the two carboxylate oxygen atoms is in the 1-plane $\left(\Delta z_{1}=\right.$ $-1)$ and the other half is neutralized by the two protons in the 0-plane $\left(\Delta z_{0}=1\right)$. Less tartrate will be adsorbed at higher background than at lower electrolyte concentrations, so introducing a $\mathrm{Na}$-tartrate ion pair outer-sphere complex was required to account properly for the data for $\mathrm{NaNO}_{3}$ concentrations $>10 \mathrm{mM}$. In fact, carboxylic acids may form dissolved ternary complexes not only with alkaline earth cations but also with alkaline cations (e.g., $\log \beta\left(\mathrm{TarNa}^{-}\right)=1.5$ [7]). One carboxylic group may therefore attract a sodium cation to form a type B ternary monodentate surface complex, as suggested for other carboxylic acids [4]. This would occur through the reaction

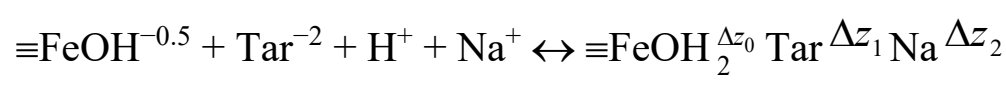

For this monodentate outer-sphere complex, the change in charge in the 1-plane increases to $\Delta z_{1}=-2$ and in the 2-plane is non-zero because of the additional monovalent cation introduced $\left(\Delta z_{2}=+1\right)$, to achieve good fits for the adsorption vs. pH curves (Figure S7) using the $\log K$ values compiled in Table 2. 

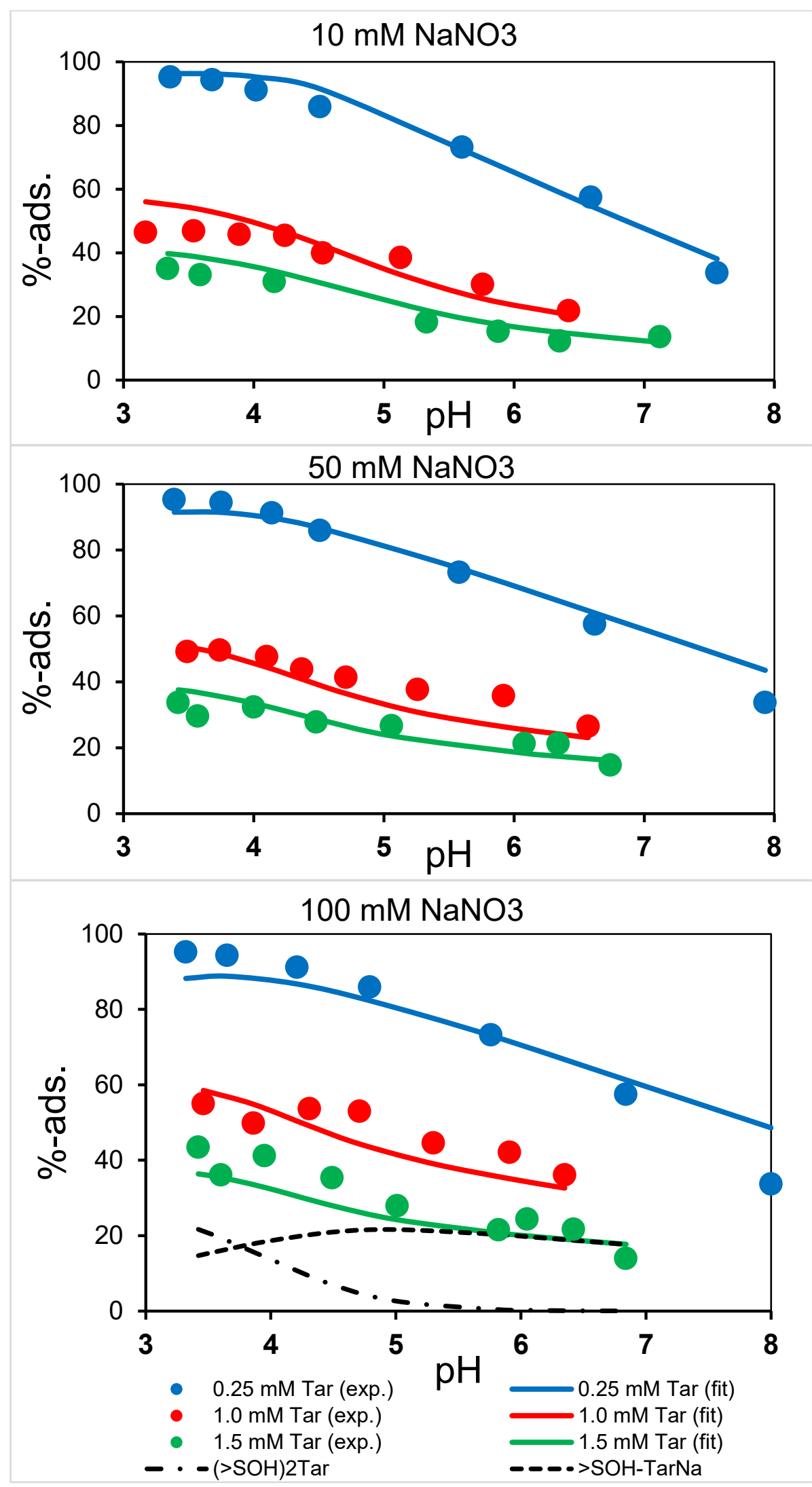

Figure S7. Experimental data (circles) and CD-MUSIC adsorption model curves for tartrate adsorption by GFH $\left(1 \mathrm{~g} \mathrm{~L}^{-1}\right)$ at different initial tartaric acid concentrations $\left(0.25-1.50 \mathrm{mmol} \mathrm{L}{ }^{-1}\right)$ and $\mathrm{NaNO}_{3}$ background electrolyte concentrations $\left(10-100 \mathrm{mmol} \mathrm{L}^{-1}\right)$. 


\section{7. $\mathrm{Sb}(\mathrm{V})$ surface complexation model}

At ambient environmental $\mathrm{pH} 4-9$, antimonite dominates as the oxyanion $\mathrm{Sb}(\mathrm{OH})_{6}^{-}[10]$ and was used as $\mathrm{KSb}(\mathrm{OH})_{6}$ for the batch adsorption experiments. As typical for an oxyanion, adsorption by iron oxyhydroxides decreases when $\mathrm{pH}$ increases (Figure S8). This is due to increased electrostatic repulsion between the more negatively charged surface above the $\mathrm{pH}_{\mathrm{pzc}}$ of 8 and the oxyanion. The model setup for adsorption of $\mathrm{Sb}(\mathrm{V})$ on $\mathrm{GFH}$ is much less complicated, since complexing organics were not added. The dissociation constant of antimonic acid has been slightly corrected at $\mathrm{p} K_{\mathrm{a}}=2.85$ from more recent literature [10]. Since the $\mathrm{Sb}(\mathrm{V})$ adsorption is much weaker than that of $\mathrm{Sb}(\mathrm{III})$, it is reasonable to introduce a monodentate outer-sphere complexation according to the CD-MUSIC model suggested by Verbeek et a. [11]:

$$
\begin{aligned}
& \equiv \mathrm{FeOH}^{-0.5}+\mathrm{Sb}(\mathrm{OH})_{6}^{-}+\mathrm{H}+\leftrightarrow \equiv \mathrm{FeOH}_{2}^{-0.5+\Delta z_{0}} \mathrm{Sb}(\mathrm{OH})_{6}^{\Delta z_{1}} \\
& 2 \equiv \mathrm{FeOH}^{-0.5}+\mathrm{Sb}(\mathrm{OH})_{6}^{-}+\mathrm{H}^{+} \leftrightarrow \equiv \mathrm{Fe}_{2} \mathrm{O}_{2}^{-0.5+\Delta z_{0}} \mathrm{HSb}(\mathrm{OH})_{4}^{\Delta z_{1}}+\mathrm{H}_{2} \mathrm{O}
\end{aligned}
$$

For the outer-sphere complex formulation (3), the charge distribution was suggested at $\Delta z_{0}=0.8$ v.u. and $\Delta z_{1}$ $=-0.8$ v.u., while for the bidentate inner-sphere complex formulation (4), a best fit was found with $\Delta z_{0}=$ 0.05 and $\Delta z_{1}=-0.05$ v.u., respectively [11]. However, the latter surface complex can be neglected over the entire $\mathrm{pH}$ range $3-11$. The fit using only the outer-sphere complex with a $\log K=12.3 \pm 0.1$ is sufficiently matching the experimental data $(\mathrm{R}=0.98)$. Nonetheless, a shift of the charge distribution of the outer-sphere complex towards the inner plane renders it a bit more towards an inner-sphere binding characteristic in agreement with EXAFS results [12].

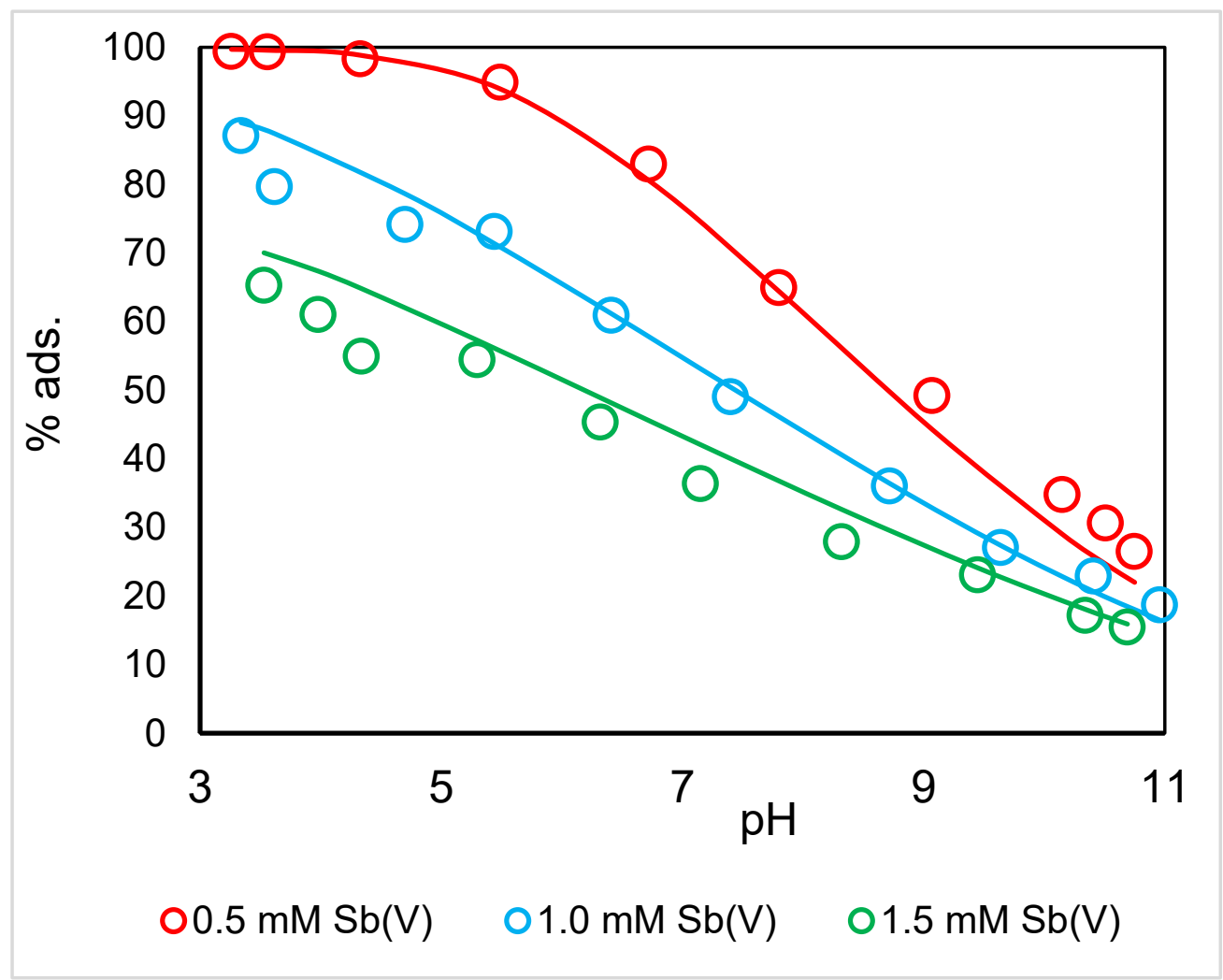

Figure S8. Experimental data (circles) and CDMUSIC adsorption model (solid curves) for $\mathrm{Sb}(\mathrm{V})$ adsorption by GFH $\left(1 \mathrm{~g} \mathrm{~L}^{-1}\right)$ at different initial $\mathrm{Sb}(\mathrm{V})$ concentrations $(0.50,1.0$ and $\left.1.50 \mathrm{mmol} \mathrm{L}^{-1}\right)$ in a $\mathrm{NaNO}_{3}$ background electrolyte solution of $10 \mathrm{mmol} \mathrm{L}^{-1}$. 


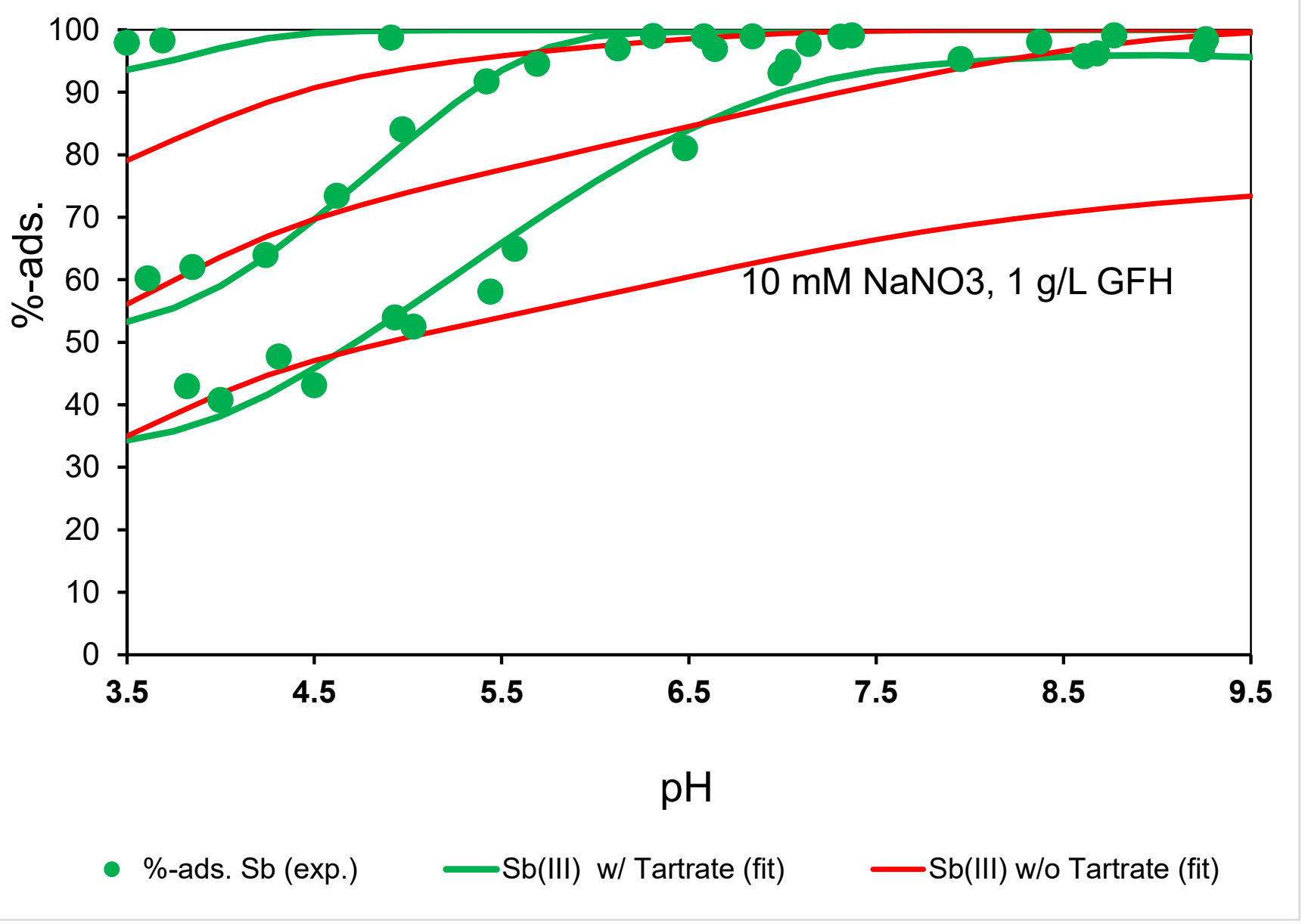

Figure S9. Experimental data (circles) and CD-MUSIC adsorption model curves for Sb(III) adsorption by GFH $\left(1 \mathrm{~g} \mathrm{~L}^{-1}\right)$ at different initial $\mathrm{Sb}(\mathrm{III})$ and tartaric acid concentrations (both 0.50, 1.0 and $1.50 \mathrm{mmol} \mathrm{L}^{-1}$ ) and $\mathrm{NaNO}_{3}$ background electrolyte concentration of $10 \mathrm{mmol} \mathrm{L}^{-1}$. The model curves were generated with and without tartrate complexation in solution. The curves with tartrate complexation were modelled with a complexation constant for the dimer enhanced by one $\operatorname{logK}$ unit $(\log \beta 23.17$ instead of 22.17), which gave a better fit $(\mathrm{R}=0.97$ instead of 0.95$)$. The fit without tartrate complexation gave a good fit for the higher $\mathrm{Sb}$ concentrations at acidic $\mathrm{pH}$ conditions only, and for the lower Sb concentration at circumneutral to alkaline $\mathrm{pH}$ conditions, both with reaction constant for the neutral surface complex reduced by $2 \log K$ units $(7.1$ instead of 9.1). 


\section{PhreePlot scripts for the pe-pH species predominance diagram (Figure 5, main text)}

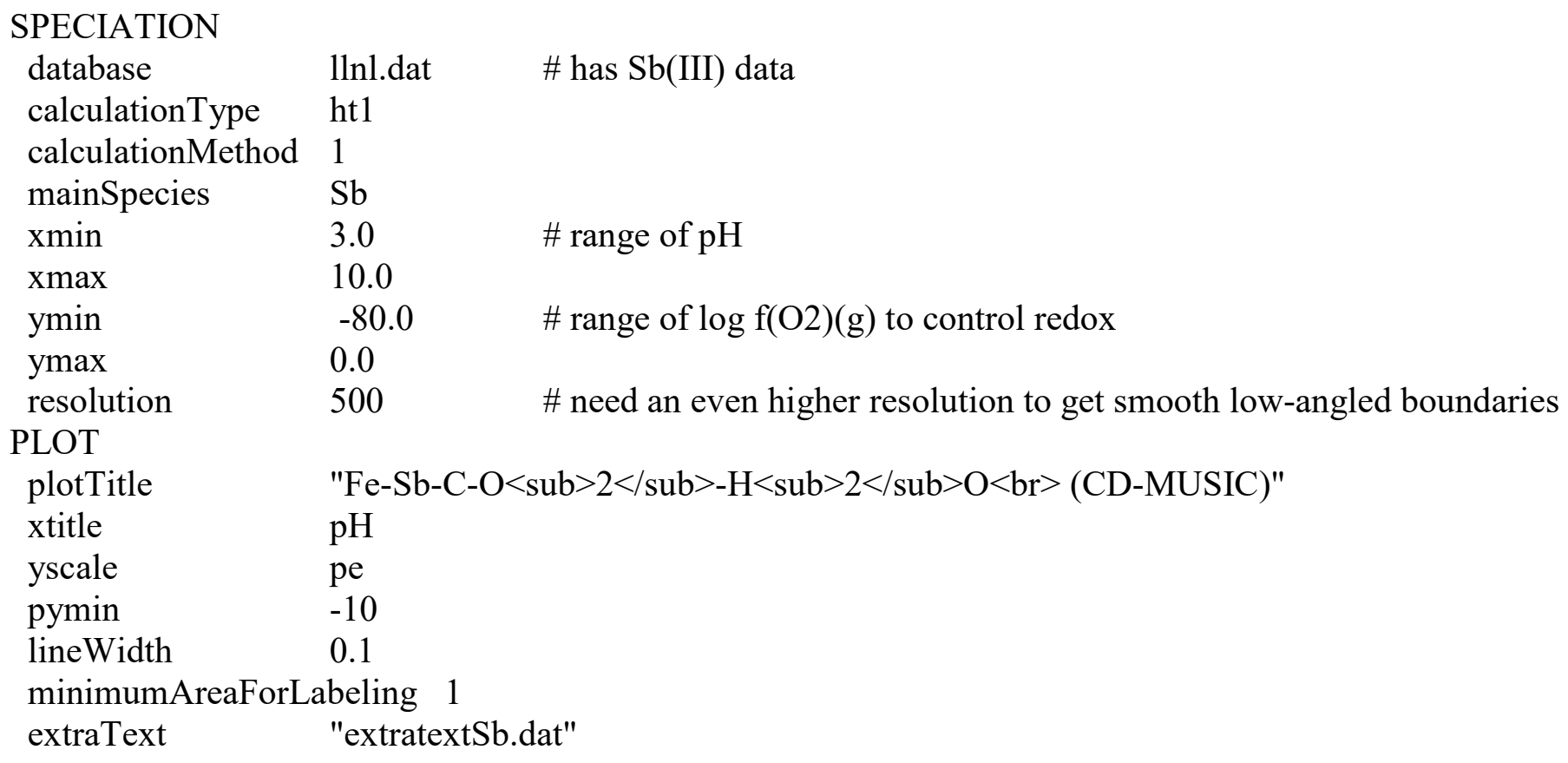

\section{CHEMISTRY}

include 'ht1s.inc' \# adds "(s)" for mineral phases to avoid confusion with neutral aq species

\section{KNOBS}

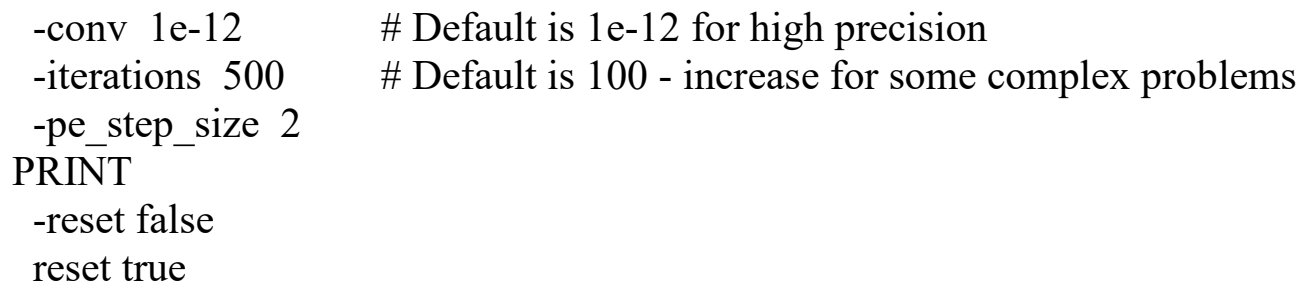

\section{SOLUTION MASTER SPECIES}

$\begin{array}{llllll}\text { Tartrate } & \text { Tartrate- } 2 & 0.0 & 148 & 148 & \text { \# tartrate not in llnl.dat database } \\ \mathrm{Sb} & \mathrm{Sb}(\mathrm{OH}) 3 & 0.0 & 173 & 122 & \\ \mathrm{Sb}(3) & \mathrm{Sb}(\mathrm{OH}) 3 & 0.0 & \mathrm{Sb}(\mathrm{OH}) 3 & \\ \mathrm{Sb}(5) & \mathrm{Sb}(\mathrm{OH}) 6- & 0.0 & \mathrm{Sb}(\mathrm{OH}) 6- & \text { \# } \mathrm{Sb}(\mathrm{V}) \text { not in llnl.dat database }\end{array}$

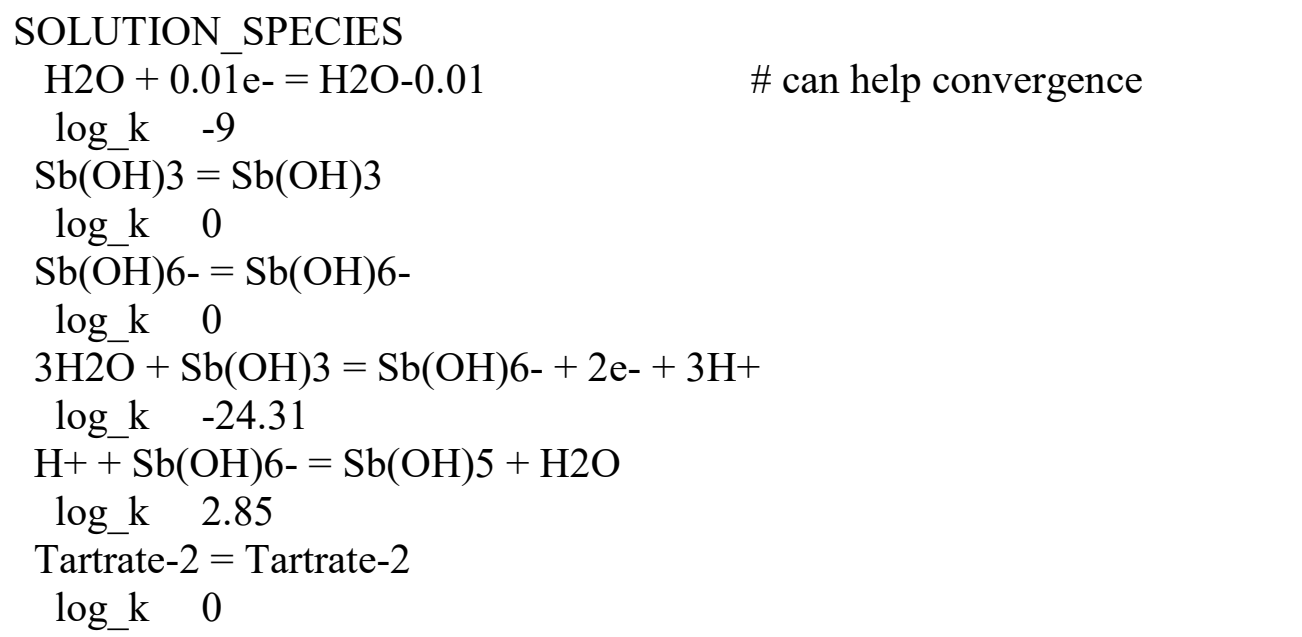




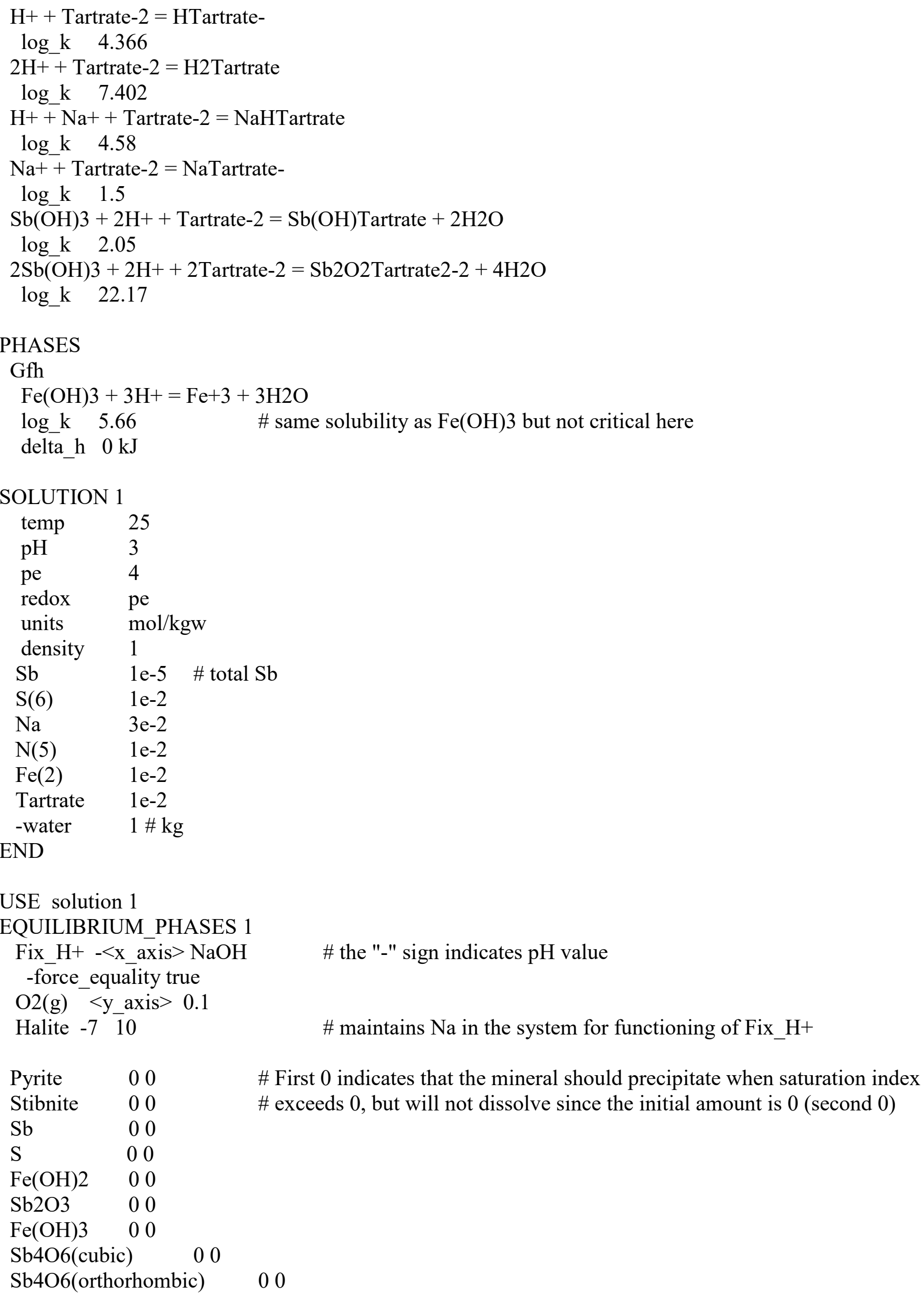


$\mathrm{Sb} 2 \mathrm{O} 5 \quad 00$

$\mathrm{Sb}(\mathrm{OH}) 3 \quad 00$

Gfh $\quad 00$

\# hematite, magnetite and goethite removed to make $\mathrm{Gfh}=\mathrm{Fe}(\mathrm{OH}) 3$ stable

\section{SURFACE_MASTER_SPECIES \\ \#\# Gfh uni Gfh uniOH-0.5 \\ \#\# Gfh_tri Gfh_triO-0.5}

Gfh_uni Gfh_uniOH1.5

Gfh_tri Gfh_triOH0.5

\section{SURFACE_SPECIES}

\# Fe3-O sites

\#\# Gfh_triO-0.5 = Gfh_triO-0.5

\#\# -cd music 000000

\#\# $\quad \log _{-} \mathrm{k} 0$

Gfh_triOH0.5 $=$ Gfh_triOH0.5

$\log \mathrm{k} 0$

Gfh_triOH0.5 $=$ Gfh_triO-0.5 $+0.5 \mathrm{H}+$

log_k 10

-cd_music -0.5000000

Gfh_triO- $0.5+\mathrm{H}+=\mathrm{Gfh} \_$triOH +0.5

$\log \mathrm{k} \quad 8.2$

-cd_music 100000

Gfh_triO-0.5 $+\mathrm{Na}+=\mathrm{Gfh} \_$triONa+0.5

$\log { }_{-} \mathrm{k} \quad-0.6$

-cd_music 010000

Gfh_triO-0.5 + H+ + NO3- = Gfh_triOHNO3-0.5

$\log _{-} \mathrm{k} \quad 7.6$

-cd_music 1 -1 10000

Gfh_uniOH1.5 = Gfh_uniOH1.5

$\log \mathrm{k} \quad 0$

Gfh_uniOH1.5 $=$ Gfh_uniOH-0.5 $+0.5 \mathrm{H}+$

$\log \_\quad 10$

-cd music -0.500000

Gfh_uniOH-0.5 $+\mathrm{H}+=\mathrm{Gfh} \_$uniOH2 +0.5

$\log \mathrm{k} \quad 8.2$

-cd music 100000

Gfh_uniOH-0.5 $+\mathrm{Na}+=\mathrm{Gfh} \_$uniOHNa +0.5

$\log \mathrm{k} \quad-0.6$

-cd_music 010000

Gfh_uniOH-0.5 + H+ + NO3- = Gfh_uniOH2NO3-0.5

$\log \mathrm{k} \quad 7.6$

-cd_music $1-10000$

$2 \mathrm{Gfh}$ - uniOH- $0.5+2 \mathrm{H}++$ Tartrate- $2=\mathrm{Gfh} \_$uni2Tartrate- $+2 \mathrm{H} 2 \mathrm{O}$

$\log \overline{\mathrm{k}} 16$

-cd_music $1-10000$

Gfh_uniOH-0.5 $+\mathrm{H}++\mathrm{Na}++$ Tartrate-2 $=$ Gfh_uniOH2TartrateNa-0.5

$\log \mathrm{k} \quad 13.8$

-cd_music 1 -2 1000

$2 \mathrm{Gfh} \_$uniOH-0.5 $+\mathrm{Sb}(\mathrm{OH}) 3=\left(\mathrm{Gfh} \_\right.$uniO $) 2 \mathrm{Sb}(\mathrm{OH})-+2 \mathrm{H} 2 \mathrm{O}$ 
log_k 9.1

-cd_music $0.66-0.66000$

$2 \mathrm{Gfh} \_$uniOH-0.5 $+\mathrm{Sb}(\mathrm{OH}) 3=\left(\mathrm{Gfh} \_\right.$uniO $) 2 \mathrm{Sb}(\mathrm{OH}) 2-2+\mathrm{H}++\mathrm{H} 2 \mathrm{O}$

$\log \overline{\mathrm{k}} \quad 2.5$

-cd_music $0.58-1.58000$

Gfh_uniOH-0.5 $+\mathrm{H}++\mathrm{Sb}(\mathrm{OH}) 6-=\mathrm{Gfh} \_$uniOH $2 \mathrm{Sb}(\mathrm{OH}) 6-0.5$

$\log \mathrm{k} \quad 12.3$

-cd_music $0.8-0.8000$

\section{SURFACE 1}

-equilibrate with solution 1

-sites DENSITY

Gfh_uni $6.1 \quad 250 \quad 1$

-capacitance $0.74 \quad 0.93$

Gfh_tri 5.3

-cd_music

END

\section{Auxiliary scripts:}

\section{Fillcolor.dat}

"(Gfh_uniO)2Sb(OH)-"

"(Gfh_uniO)2Sb(OH)2-2"

orange1

orange 3

"Gfh_uniOH2Sb(OH)6-0.5"

yellow1

"HSb2S4-"

blue 1

"Sb2S4-2"

"O2(g)> $0.21 \mathrm{~atm} "$

"Sb2O2Tartrate2-2"

blue4

white

"Sb2O5(s)"

"Sb(OH)2+"

green 1

yellow2

"Sb(OH)3"

"Sb(OH)3(s)"

blue3

sky1

gray1

"Sb(OH)4-"

gray3

"Sb(OH)6-"

yellow2

"Sb(OH)Tartrate"

green2

"Sb(s)"

gray4

"Stibnite(s)"

gray2

\section{extratextSb.dat}

$\# 1$ auto auto "<input:SPECIATION,>" 2 blue 00

1716 "Sb $1 \mathrm{e}<$ sup $>-5</$ sup $>$ mol/L" 3 black 00 


\section{References}

[1] Barrios, E.; Hernán, L.; Morales, J.; Tirado J. Effect of grinding in synthetic akaganeite. J. Colloid Interf. Sci. 1986, 113, 212-217.

[2] Post, J.E.; Heaney, P.J.; Von Dreele, R.B.; Hanson, J.C. Neutron and temperature-resolved synchrotron X-ray powder diffraction study of akaganéite. Am. Min. 2003, 88, 782 - 788.

[3] Kersten, M.; Karabacheva, S.; Vlasova, N.; Branscheid, R.; Schurk, K.; Stanjek, H. Surface complexation modeling of arsenate adsorption by akaganéite $(\beta-\mathrm{FeOOH})$-dominant granular ferric hydroxide. Colloids and Surfaces A 2014, 448, 73-80.

[4] Chater, R.; Gavarri, J.R.; Hewat. A.W. Structures isomorphes $\mathrm{MeX}_{2} \mathrm{O}_{4}$. Evolution structurale entre $2 \mathrm{~K}$ et $300 \mathrm{~K}$ de l'antimonite $\mathrm{FeSb}_{2} \mathrm{O}_{4}$ : elasticite et ordre magnetique anisotropes. J. Solid State Chem. 1985, 60, $78-86$.

[5] Berlepsch, P.; Armbruster, Th.; Brugger, J.; Criddle, A.J.; Graesere, S. Tripuhyite, FeSbO4, revisited. Min. Mag. 2003, 67, $31-46$.

[6] Filius, J.D.; Hiemstra, T.; Van Riemsdijk, W.H. Adsorption of small weak organic acids on goethite: Modeling of mechanisms. J. Colloid Interf. Sci. 1997, 195, 368-380.

[7] Cornell, R.M.; Schindler, P.W. Infrared study of the adsorption of hydroxycarboxylic acids on $\alpha-\mathrm{FeOOH}$ and amorphous Fe(III)hydroxide. Colloid Polymer Sci. 1980, 258, 1171-1175.

[8] Boily, J.-F.; Persson, P.; Sjöberg, S. Benzenecarboxylate surface complexation at the goethite $(\alpha-$ $\mathrm{FeOOH}$ )/water interface: II. Linking IR spectroscopic observations to mechanistic surface complexation models for phthalate, trimellitate, and pyromellitate. Geochim. Cosmochim. Acta 2000, 64, 3453-3470. [9] Zelenina, T.E.; Zelenin, O.Y. Complexation of citric and tartaric acids with $\mathrm{Na}$ and $\mathrm{K}$ ions in aqueous solution. Russ. J. Coordinat. Chem. 2005, 31, 235-242.

[10] Accornero, M.; Marini, L.; Lelli, M. The dissociation constant of antimonic acid at $10-40{ }^{\circ} \mathrm{C}$. $J$. Solution Chem. 2008, 37, 785-800.

[11] Verbeek, M.; Warrinnier, R.; Gustafsson, J.P.; Thiry, Y.; Smolders, E. Soil organic matter increases antimonate mobility in soil: $\mathrm{An} \mathrm{Sb}(\mathrm{OH})_{6}$ sorption and modelling study. Appl. Geochem. 2019, 104, 33-41. [12] Scheinost, A.C.; Rossberg, A.; Vantelon, D.; Xifra, I.; Kretzschmar, R.; Leuz, A.-K.; Funke, H.; Johnson, C.A. Quantitative antimony speciation in shooting-range soils by EXAFS spectroscopy. Geochim. Cosmochim. Acta 2006, 70, 3299-3312. 